\title{
Postoperative chemoradiotherapy improves survival in esophageal squamous cell cancer with extracapsular lymph node extension
}

\author{
Z. W. WANG ${ }^{1,2,3}$, Z. P. LUAN ${ }^{1,2}$, W. ZHANG ${ }^{1,2}$, W. DONG ${ }^{1,2}$, C. R. FU' ${ }^{2}$, Y. N. WANG ${ }^{3}$, B. S. LI ${ }^{2, *}$ \\ ${ }^{1}$ Department of Radiation Oncology, Cancer Hospital, Tianjin Medical University, Tianjin, P.R.China; ${ }^{2}$ Department of Radiation Oncology, \\ Shandong Cancer Hospital, Shandong Academy of Medical Sciences, Jinan, P.R.China; ${ }^{3}$ Department of Radiation Oncology, Tangshan People's \\ Hospital, Tangshan, P.R.China
}

*Corresponding author: baoshli@yahoo.com

Received February 28, 2014 / Accepted April 2, 2014

\begin{abstract}
In esophageal squamous cell carcinoma (ESCC), extracapsular extention (ECE) in metastatic lymph nodes portends high rate of recurrence and poor prognosis. To our knowledge, the effectiveness of postoperative chemoradiotherapy (CRT) in these patients has never been investigated. In this retrospective study, we compared the outcomes of surgery with or without postoperative chemoradiotherapy in ESCC patients with ECE. From 2008 to 2009, 90 ECSS patients with ECE were included. Among those patients, 47 only received curative surgery alone, and 43 received additional postoperative concurrent CRT which consisted of radiotherapy (median dose $50 \mathrm{~Gy}$ ) and chemotherapy (5-fluorouracil $1000 \mathrm{mg} / \mathrm{m}^{2}$, days 1-4 and 29-32; cisplatinum $25 \mathrm{mg} / \mathrm{m}^{2}$, days 1-3 and 29-31). Patients treated with postoperative CRT had significantly more T3/4 tumors ( $p=0.023$ ). Based on log-rank stratified by T stage, postoperative adjuvant CRT significantly improved the overall survival $(p=0.017)$ and progression free survival $(p=0.002)$. In multivariate analysis, adjuvant CRT was identified as an independent prognostic factor $(\mathrm{HR}=0.494$, CI $0.290-0.844, p=0.010)$. Compared with surgery alone, the CRT group had significantly fewer cases of regional recurrence $(P=0.048)$ and overall recurrence $(P=0.024)$. However, there was no significant difference in distant metastasis between two groups $(P=0.755)$. In conclusion, our data suggest that the postoperative adjuvant $\mathrm{CRT}$ might be beneficial in selected subgroups of ESCC patients with ECE. To further verify these results, a prospective trial with a large sample size is needed.
\end{abstract}

Key words: esophageal squamous cell cancer, adjuvant treatment, chemoradiotherapy, extracapsular extension

Esophageal cancer is an aggressive malignancy with a poor prognosis. It is the eighth most common malignant tumor and sixth most common cause of cancer deaths worldwide [1]. In China, the majority of cases are esophageal squamous cell carcinoma (ESCC) [2]. Surgery may be the initial treatment; however, patients with stages beyond T1b should undergo multidisciplinary evaluation and be considered for multimodality therapy. Surgery alone to treat esophageal cancer results in high rates of locoregional recurrence and distant metastasis [3]. Therefore, multimodal therapy that includes radiotherapy (RT), chemotherapy (CT), and surgery has been increasingly used in the treatment of esophageal cancer. Adjuvant RT has been evaluated in several randomized controlled trials [4-8]. Disappointingly, most of them failed in improvement of OS with the addition of RT to surgery. The high rate of recurrence and poor prognosis still make us believe that some high-risk subgroups of patients with ESCC may benefit from adjuvant therapy.

It is well known that extracapsular extention (ECE) of metastatic lymph nodes is associated with a poor prognosis in multiple tumor types, such as head and neck squamous cell carcinoma (HNSCC) and gastrointestinal malignancies [9-11]. Moreover, ECE in HNSCC is not only a prognostic factor, but also an adjuvant therapy determinant, because adjuvant chemoradiotherapy (CRT) has been demonstrated to improve locoregional control and survival of HNSCC patient with ECE in several multicenter randomized studies [12]. The role of ECE as a prognostic factor has also been well established in ESCC [13-16]. However, unlike the ECE positive HNSCC which has a higher local recurrence rate than the ECE negative ones, the recurrence pattern of ESCC patients with ECE is still controversial. Some studies $[13,15]$ reported that ECE in ESCC 
patients was an indicator of distant organ recurrence, whereas others [14] found local and distant recurrence rates were equally high. All in all, in ECE positive ESCC local recurrence is no longer the sole focus of attention, as the distant recurrence is also important. The CRT which combined RT and CT may play a role in both local and systematic disease and seems to be a good treatment option for the ESCC patients with ECE. For these reasons, we infer that adjuvant CRT may reduce recurrence and improve the survival in patients with ECE positive ESCC. To our knowledge, no previous studies have investigated the effect of adjuvant treatment on the ECE positive ESCC so far. In this retrospective study, we investigate the therapeutic impact of adjuvant CRT in ESCC patients with ECE.

\section{Patients and methods}

Patients. The eligibility criteria were as follows: (1) patients had histologically proven ESCC with at least one ECE positive lymph node; (2) patients had received transthoracic esophagectomy with extensive lymphadenectomy, using either two-field or three-field approach and achieved R0 status; (3) at least 15 lymph nodes had been removed; (4) patients had not received preoperative cancer therapy; (5) karnofsky performance status was $\geq 70$. (6) patients had received curative surgery alone or surgery plus adjuvant CRT.

Surgery. Three different procedures were used. For patients with tumors in the upper third of the thoracic segment, a standard esophagectomy was performed by a three-phase abdominothoracic McKeown method, and three-field (thoracoabdominal and cervical) lymph node dissection was also performed if indicated. For tumors in the mid and lower third, Ivor-Lewis or left thoracoabdominal esophagectomy techniques were employed and two-field (thoracoabdominal) lymph node dissection was performed. In each case, lymph nodes were removed as completely as possible.

Postoperative adjuvant chemoradiotherapy. Radiation therapy started 3 to 6 weeks after surgery. Treatment was delivered on linear accelerators using 6-15 MV photon beams. Either a two-dimensional (2D) or a conformal three-dimensional treatment (3D) planning was used for delivery of therapy based on the preference of the radiation oncologist. The field borders were defined based on pretreatment investigations and imaging, correlated with the patient's postoperative anatomy. The RT field included a minimum 5-cm margin from the superior and inferior margins of the tumor bed and a width of $6-8 \mathrm{~cm}$. For tumors in the upper third of thoracic esophagus, supraclavicular fossae was included in the field, while the celiac lymph nodes were included for lower thoracic tumors. The total dose was 45-54 Gy (median dose 50 Gy) in 20-25 fractions within 5 weeks. In 2D, radiation was given through anteroposterior fields first at $40 \mathrm{~Gy}$ (1.8-2 Gy per fraction), followed by parallel opposing oblique fields at $5-14$ Gy to avoid the spinal cord. For 3D planning total spinal cord radiation dose was limited to $4500 \mathrm{cGy}$ and the double lung V20 dose was $<30 \%$.
In the same period during RT, two cycles of CT were performed. The CT regimen comprised protracted 5 -fluorouracil infusion $\left(1000 \mathrm{mg} / \mathrm{m}^{2}\right.$, days $1-4$ and $\left.29-32\right)$ and a 2-hour infusion of cisplatinum (25 mg/m $\mathrm{m}^{2}$, days $1-3$ and 29-31). A prophylactic antiemetic was given during $\mathrm{CT}$, and supportive care and symptomatic treatment were provided as well.

Follow-Up. Patients were routinely evaluated for tumor control every 3-4 months for the first year, every 6 months for the next 2 years, and then annually thereafter. Procedures included a careful clinical examination, routine blood tests, barium swallow, thoracic computer tomography (CT), and abdominal ultrasound. Further evaluations were carried out only if clinical findings suggested a progression of the disease.

Outcome. The primary endpoint was overall survival (OS), defined as the time from the date of surgery to the date of death for any cause or the last known date that the patient was alive. Progression free survival (PFS) was the secondary endpoint which was defined as time from the date of diagnosis until the earliest date of locoregional recurrence, distant metastasis, death from any cause, or the date of last follow-up. The pattern of recurrence was also recorded. Recurrence was classified as local recurrence, regional lymph node recurrence, or distant recurrence. Because of the manner of tumor spread through the lymphatic system, cervical, celiac axis and paraaortic node metastases were classified as lymph node recurrence in this study. Treatment-related toxicities were assessed according to version Radiation Therapy Oncology Group/European Organization for Research and Treatment of Cancer (1992) criteria [17].

Statistical methods. Categorical variables were expressed as numbers and percentages and quantitative variables as the mean or median with interquartile range. The differences in clinical factors between groups were assessed by $\mathrm{X}^{2}$ test or Fisher's exact test. The Kaplan-Meier method was applied for outcome analysis of OS and PFS. Statistical significance was tested by stratified log-rank test. Cox regression was used to identify the independent predictors of outcome. Two-sided $p$ values $<0.05$ were considered statistically significant. The statistical analyses were performed using SPSS (version 16.0 for Windows).

\section{Results}

Characteristics of patients. From 2008 to 2009, a total of 90 patients from two centers met the eligibility criteria. Of them, 47 (52.2\%) received curative surgery alone and 43 $(47.8 \%)$ received adjuvant CRT after surgery. Characteristics of the patients were summarized in table 1 . There was no difference in the baseline characteristics between the surgery and adjuvant treatment groups except $\mathrm{T}$ stage. The number of patients with the $\mathrm{T} 4$ stage was larger in the adjuvant treatment group $(P=0.023)$.

Survival. The median follow-up time was 26.5 months, ranging from 6.5 to 70 months. For the entire cohort of patients, the overall survival rates at 1,3 , and 5 years were 


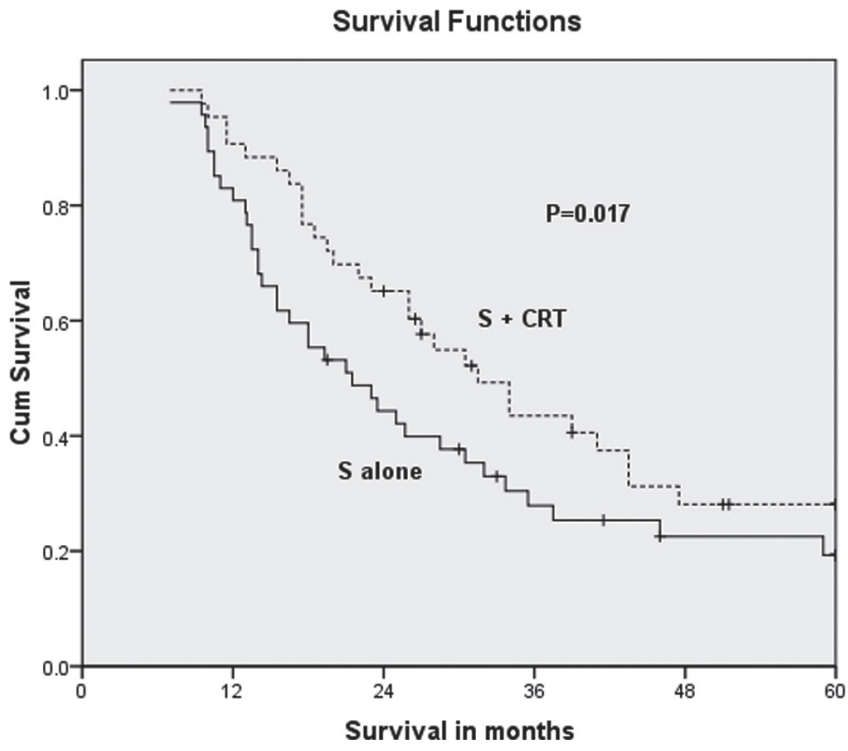

Figure 1. Overall survival of patients with extracapsular extension positive esophageal squamous cell carcinoma received either surgery plus postoperative chemoradiotherpay(CRT) or surgery (S) alone.

Table 1. Characteristics of patients in each group

\begin{tabular}{|c|c|c|c|c|}
\hline \multirow{2}{*}{ Characteristic } & \multicolumn{2}{|c|}{ No. of patients (\%) } & \multirow{2}{*}{$\mathrm{X}^{2}$} & \multirow{2}{*}{$P$ value } \\
\hline & Surgery Only & Surgery + CRT & & \\
\hline Sex & & & 0.045 & 0.833 \\
\hline Male & $38(80.9 .0)$ & $34(79.1)$ & & \\
\hline Female & $9(19.1)$ & $9(20.9)$ & & \\
\hline Age & & & 1.683 & 0.195 \\
\hline$<60$ & $22(46.8)$ & $26(60.5)$ & & \\
\hline$\geq 60$ & $25(53.2)$ & $17(39.5)$ & & \\
\hline Primary tumor stage & & & 7.504 & 0.023 \\
\hline $\mathrm{T} 1,2$ & $12(25.5)$ & $3(7.0)$ & & \\
\hline T3 & $30(63.8)$ & $29(67.4)$ & & \\
\hline $\mathrm{T} 4$ & $5(10.6)$ & $11(25.6)$ & & \\
\hline Nodal stage & & & 0.124 & 0.940 \\
\hline N1 & $18(38.3)$ & $15(34.9)$ & & \\
\hline N2 & $18(38.3)$ & $17(39.5)$ & & \\
\hline N3 & $11(23.4)$ & $11(25.6)$ & & \\
\hline Disease stage & & & 5.828 & 0.120 \\
\hline IIB & $9(19.1)$ & $2(4.7)$ & & \\
\hline IIIA & $10(21.3)$ & $13(30.2)$ & & \\
\hline IIIB & $15(31.9)$ & $11(25.6)$ & & \\
\hline IIIC & $13(27.7)$ & $17(30.5)$ & & \\
\hline Tumor location & & & 1.468 & 0.226 \\
\hline Upper, middle & $27(57.4)$ & $30(69.8)$ & & \\
\hline Lower & $20(42.6)$ & $13(30.2)$ & & \\
\hline Differentiation & & & 0.551 & 0.458 \\
\hline Well, moderate & $34(72.3)$ & $34(79.1)$ & & \\
\hline Poor & $13(27.7)$ & $9(20.9)$ & & \\
\hline
\end{tabular}

Abbreviations: CRT, chemoradiotherapy.

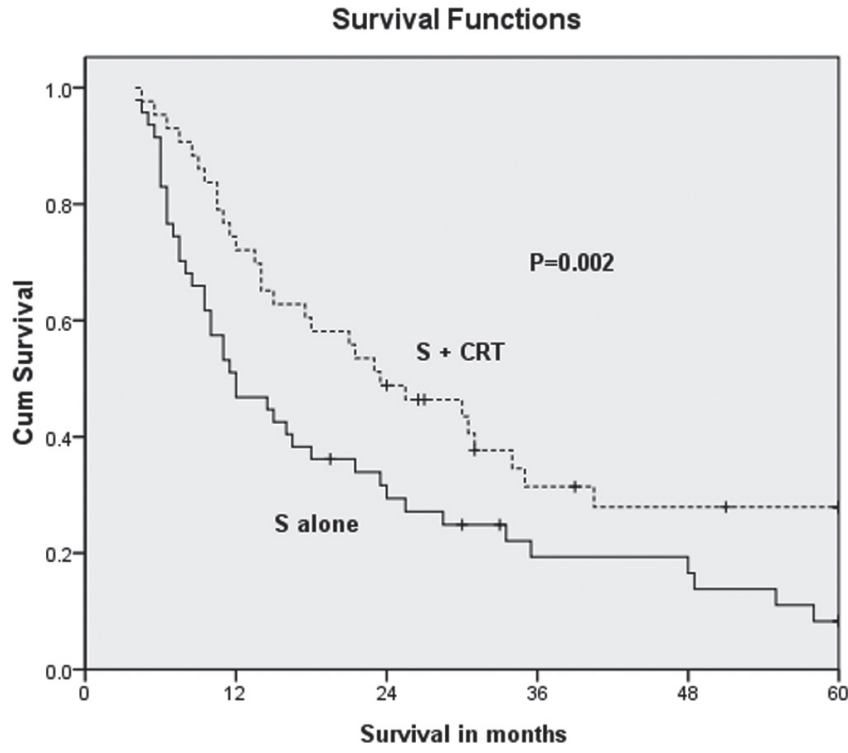

Figure 2. Progression free survival of patients with extracapsular extension positive esophageal squamous cell carcinoma received either surgery plus postoperative chemoradiotherpay (CRT) or surgery (S) alone.

$85.6 \%, 35.4 \%$, and $23.4 \%$, respectively. Median survival time was 26.0 months. The overall survival curves for patients treated with surgery alone or combined modality are shown in Figure 1. 5-year survival rates were 19.3\% for the surgery only group and $28.1 \%$ for the surgery plus postoperative CRT group. Postoperative CRT showed a statistically significant better overall survival ( $p=0.017, \log$-rank test stratified by T stage). The 1-year, 3-year and 5-year PFS rates were 58.9\%, $25.1 \%$ and $17.0 \%$ for the whole group, and the median PFS was 16.5 months. The 5 -year PFS rate was $27.9 \%$ in the combined modality group, while in the surgery alone group, the 5 -year PFS rate was $8.3 \%$. CRT provided more benefit in PFS compared to surgery alone ( $p=0.002, \log$-rank test stratified by T stage).

Univariate and multivariate analyses factors. The clinical characteristics of patients were evaluated to determine the prognostic value in terms of OS (Table 2). Univariate analysis showed that overall survival was significantly associated with $\mathrm{N}$ stage $(p<0.001)$, differentiation $(p=0.011)$, and adjuvant CRT $(p=0.017)$. In multivariate analysis, $\mathrm{T}$ stage $(p=0.024), \mathrm{N}$ stage $(p=0.001)$, and adjuvant CRT $(p=0.010)$ were identified as independent prognostic factors.

Patterns of failure. In the surgery alone group, progression in regional lymph nodes was observed in 25 (53.2\%) patients, distant relapse was observed in $19(40.4 \%)$ patients, and both occurred in $4(8.5 \%)$ patients; however, in the surgery plus postoperative CRT group, 14 (32.6\%) patients had progression in regional lymph nodes, and $16(38.9 \%)$ patients had progression at distant sites. Compared with surgery alone group, the surgery plus CRT group had significantly decreased the number of cases in regional recurrence $(P=0.048)$ and overall 
Table 2. Univariate analysis of the prognostic factors for overall survival

\begin{tabular}{|c|c|c|c|c|c|}
\hline \multirow{2}{*}{ Characteristic } & \multicolumn{5}{|c|}{ Univariate analysis } \\
\hline & 3-y survival rate (\%) & 5-y survival rate (\%) & MST (moth) & $\mathrm{X}^{2}$ & $P$ value \\
\hline Sex & & & & 0.349 & 0.555 \\
\hline Male & 35.7 & 22.3 & 25.7 & & \\
\hline Female & 34.0 & 27.2 & 33.7 & & \\
\hline Age & & & & 0.000 & 0.986 \\
\hline$<60$ & 35.6 & 21.6 & 27.0 & & \\
\hline$\geq 60$ & 35.1 & 24.6 & 25.7 & & \\
\hline T stage & & & & 3.987 & 0.136 \\
\hline $\mathrm{T} 1,2$ & 58.7 & 44.0 & 59.0 & & \\
\hline T3 & 32.9 & 20.7 & 23.5 & & \\
\hline $\mathrm{T} 4$ & 22.5 & 15.0 & 26.0 & & \\
\hline Nodal stage & & & & 16.482 & $<0.001$ \\
\hline N1 & 41.9 & 33.9 & 33.7 & & \\
\hline $\mathrm{N} 2$ & 40.2 & 24.1 & 28.5 & & \\
\hline N3 & 8.3 & 8.3 & 17.5 & & \\
\hline Differentiation & & & & 6.432 & 0.011 \\
\hline Well+ moderate & 41.9 & 30.0 & 30.5 & & \\
\hline Poor & 15.6 & 5.2 & 17.5 & & \\
\hline Treatment & & & & 5.682 & 0.017 \\
\hline Surgery only & 27.9 & 19.3 & 21.5 & & \\
\hline Surgery+ CRT & 43.5 & 28.1 & 31.5 & & \\
\hline
\end{tabular}

Abbreviation: MST, Median survival time; CRT, chemoradiotherapy.

recurrence $(P=0.024)$ (Table 3$)$. However, there was no difference in distant metastasis between two groups $(P=0.755)$.

Toxicities. Toxicities related to postoperative CRT are summarized in Table 5. Acute toxicities were common but manageable. There were $8(18.6 \%)$ patients suffered from grade 3-4 hematological toxicities and $1(2.3 \%)$ suffered a grade 4 esophagitis which developed an esophagus fistula. No patients developed grade 3 or worse late toxicities. Four (9.3\%) patients developed mild pulmonary fibrosis, $2(4.7 \%)$ suffered grade 1 cardiac toxicities and $1(2.3 \%)$ had grade 2 esophageal stenosis. There were no toxic deaths.

\section{Discussion}

In present study, we first investigated the impact of post-operative CRT in ESCC patients with nodal ECE. Our results showed that postoperative adjuvant CRT significantly reduced local recurrence rates, improved the OS and PFS of the ESCC patients with ECE. Multivariate analysis demonstrated that $\mathrm{T}$ stage, $\mathrm{N}$ stage, and adjuvant CRT were independent prognostic factors. Regarding the safety, we found the concurrent CRT was well tolerated with rare unmanageable toxicities.

Five randomized controlled trials (RCT) [4-8] have evaluated the role of postoperative radiotherapy after surgery compared with surgery alone. Disappointingly, most of them
Table 3. Multivariate analysis of the prognostic factors for overall survival

\begin{tabular}{|c|c|c|c|}
\hline Characteristic & HR & $95 \% \mathrm{CI}$ & $P$ value \\
\hline \multicolumn{4}{|l|}{ Sex } \\
\hline Male & 1 & & \\
\hline Female & 0.719 & $0.373-1.383$ & 0.323 \\
\hline \multicolumn{4}{|l|}{ Age } \\
\hline$<60$ & 1 & & \\
\hline$\geq 60$ & 1.070 & $0.639-1.792$ & 0.796 \\
\hline \multicolumn{4}{|c|}{ Primary tumor stage } \\
\hline $\mathrm{T} 1,2$ & 1 & & \\
\hline $\mathrm{T} 3$ & 2.793 & $1.195-6.526$ & 0.018 \\
\hline $\mathrm{T} 4$ & 3.078 & $1.163-8.147$ & 0.024 \\
\hline \multicolumn{4}{|l|}{ Nodal stage } \\
\hline N1 & 1 & & \\
\hline N2 & 1.075 & $0.569-2.032$ & 0.824 \\
\hline N3 & 3.014 & $1.553-5.846$ & 0.001 \\
\hline \multicolumn{4}{|l|}{ Differentiation } \\
\hline Well, moderate & 1 & & \\
\hline Poor & 1.610 & $0.913-2.840$ & 0.100 \\
\hline \multicolumn{4}{|l|}{ Treatment } \\
\hline Surgery only & 1 & & \\
\hline Surgery+CRT & 0.494 & $0.290-0.844$ & 0.010 \\
\hline
\end{tabular}

Abbreviation: CRT, chemoradiotherapy. 
Table 4. Sites of treatment failure

\begin{tabular}{|c|c|c|c|c|}
\hline \multirow[b]{2}{*}{ Site of recurrence } & \multicolumn{2}{|c|}{ Patients (\%) } & \multirow[b]{2}{*}{$\mathrm{X}^{2}$} & \multirow[b]{2}{*}{$\mathrm{P}$ values } \\
\hline & $\begin{array}{l}\text { Surgery Only } \\
(\mathrm{n}=47)\end{array}$ & $\begin{array}{c}\text { Surgery + CRT } \\
(\mathrm{n}=43)\end{array}$ & & \\
\hline Regional lymph nodes & $25(53.2 \%)$ & $14(32.6 \%)$ & 3.893 & 0.048 \\
\hline Cervical region & $6(12.8 \%)$ & $3(7.0 \%)$ & & \\
\hline Mediastinal region & $13(27.7 \%)$ & $8(18.6 \%)$ & & \\
\hline Celiac region & $9(19.1 \%)$ & $4(9.3 \%)$ & & \\
\hline Tumor bed & $1(2.1 \%)$ & $0(0 \%)$ & - & $1.000^{*}$ \\
\hline Distant site & $19(40.4 \%)$ & $16(38.9 \%)$ & 0.098 & 0.755 \\
\hline Mixed & $4(8.5 \%)$ & $1(2.3 \%)$ & - & $0.363^{*}$ \\
\hline Overall & $41(87.2 \%)$ & $29(67.4 \%)$ & 5.089 & 0.024 \\
\hline
\end{tabular}

Abbreviations: CRT, chemoradiotherapy; ${ }^{\star}$ Fisher's exact test

Table 5. Toxicity reaction of chemoradiothapy

\begin{tabular}{lcc}
\hline Toxicity & $\begin{array}{c}\text { Patients } \\
(\mathrm{n}=43)\end{array}$ & $\%$ \\
\hline Acute toxicities & 38 & 88.4 \\
Hematological & 30 & 69.8 \\
Grade 1-2 & 8 & 18.6 \\
Grade 3-4 & 27 & 62.8 \\
Esophagus & 26 & 60.5 \\
$\quad$ Grade 1-2 & 1 & 2.3 \\
Grade 4 & & 60.5 \\
Gastrointestinal & 26 & \\
Grade 1-2 & & 4.7 \\
Late toxicities & & \\
Cardiac & 2 & 9.3 \\
Grade 1 & & \\
Pulmonary & 4 & \\
Grade1-2 & & \\
Esophagus & & \\
Grade 2 & & \\
\hline
\end{tabular}

failed to demonstrate any improvement in OS with the addition of RT to surgery. A study from France [5] reported that post RT did not provide any survival benefits to ESCC patients regardless of lymph node status. In our study, the total radiation dose was 45-54 Gy (median dose 50 Gy) in 20-25 fractions within 5 weeks. Teniere et al. employed a similar schedule using 5 fractions per week and 1.8 Gy per fraction to total doses of 45-55 Gy. It is appeared that the differences in outcomes between our study and that of Teniere et al. were not due to the radiation dose and frequency. We noticed that Teniere et al. included patients with positive celiac nodes (stage M1a, AJCC 2002). These patients represent a cohort at much higher risk for distant failure and therefore are less likely to benefit from adjuvant RT alone. However, the adjuvant treatment strategy in our study was CRT, rather than RT. The addition of CT to RT may not only have a radiosensitizing effect, but also play a role in systemic cancer progression. So, we speculate that different adjuvant treatment modalities may contribute to the different results and the combined modality therapy with radiotherapy and chemotherapy may be superior to radiotherapy alone. To our knowledge, the efficacy of adjuvant CRT has not been compared with surgery alone in a randomized trial in patients with ESCC. The positive result from our study supported the use of postoperative CRT in ESCC with ECE.

A RCT from China [7], Xiao and colleagues also found no survival benefit for the entire cohort with the addition of adjuvant RT. When stratifying based on stage, however, there was a significant survival benefit with adjuvant RT for stage III patients. In a series of retrospective studies, Chen and colleagues $[18,19]$ analyzed some clinical data of a large sample of patients with ESCC, and reported that postoperative RT was associated with better survival for patients with node-positive ESCC. In further analysis, they found the main beneficiaries of postoperative RT were the patients with three or more positive nodes. In summary, the majority of the available evidence currently reveals that only selected locally advanced esophageal SCC are likely to benefit from adjuvant treatment. It should be noted that the ECE status was not investigated in all the studies. Our results suggested that ECE status was a new indicator for the post CRT of ESCC patients.

Sakai M et al [13] and Baba et al. [15] reported that the 5year OS of the ESCC patients with ECE was $17.9 \%$ and $14 \%$, respectively. In our study, the 5-year OS is $19.3 \%$ in the surgery only group, which was similar to those studies. Encouragingly, the use of postoperative CRT provided a significant improvement in OS compared with surgery alone and the absolute improvement in overall survival was $8.8 \%$ at 5 years. In the analysis of recurrence pattern, we found the loco-regional recurrence rate was significantly lower in patients received CRT than those received surgery alone, but there were no significant differences in distant metastases between the two groups. It seems that the prolonged OS in the CRT arms still largely benefits from the reduction in local-regional recurrence. This suggests that chemotherapy may fail to eradicate micro-metastases. Further studies are needed to identify more effective chemotherapy program. In addition, two studies $[20,21]$ reported that ECE status of esophageal cancer was an independent negative prognostic factor not influenced by neoadjuvant CRT. It is also indicated that patients with ECE may need more effective or intensified adjuvant treatment.

In the analysis of safety, we found the risk of Grade 3 or 4 adverse events was rare except for the hematological toxicity with a rate of $18.6 \%$. However, hematological toxicity currently is a manageable adverse effect, especially with the use of granulocyte colony-stimulating factor [22]. So, CRT was well tolerated by patients.

There are several potential limitations in our study. Firstly, because this is a retrospective study, some bias may be unavoidable. In the analysis of baseline characteristics, we found the $\mathrm{T}$ stages between two groups were not balanced. To overcome 
this issue, the log-rank test stratified by $\mathrm{T}$ stage was used to compare PFS and OS. Furthermore, a Cox proportional hazards model was used to identify significant factors. As a result, both of the statistical methods identified the CRT as an independent prognostic factor. The consistency of the results across statistical methods suggested that the result is robust. Secondly, in this study, most patients received 2D conventional treatment. Compared with 3D-RT, 2D-RT may reduce the therapeutic effect and increase the therapeutic side effects. The third limitation of our present study is the small sample size which may limit the power of the analysis and suggesting that the results should be interpreted with some caution.

In conclusion, for the ESCC patients with nodal ECE, postoperative adjuvant CRT significantly reduced local recurrence rates and improved the PFS and OS compared with surgery alone. To further verify these findings, a prospective trial with a large sample size is needed.

\section{References}

[1] FERLAY J, SHIN HR, BRAY F, FORMAN D, MATHERS C, et al. Estimates of worldwide burden of cancer in 2008: Globocan 2008. Int J Cancer 2010; 127: 2893-2917. http://dx.doi. org/10.1002/ijc.25516

[2] CHENG J, KONG L, HUANG W, LI B, LI H, et al. Explore the radiotherapeutic clinical target volume delineation for thoracic esophageal squamous cell carcinoma from the pattern of lymphatic metastases. J Thorac Oncol 2013; 8: 359-365.

[3] NAKAGAWA S, KANDA T, KOSUGI S, OHASHI M, SUZUKI $\mathrm{T}$, et al. Recurrence pattern of squamous cell carcinoma of the thoracic esophagus after extended radical esophagectomy with three-field lymphadenectomy. J Am Coll Surg 2004; 198: 205211. http://dx.doi.org/10.1016/j.jamcollsurg.2003.10.005

[4] FOK M, SHAM JS, CHOY D, CHENG SW WONG J. Postoperative radiotherapy for carcinoma of the esophagus: A prospective, randomized controlled study. Surgery 1993; 113: $138-147$.

[5] TENIERE P, HAY JM, FINGERHUT A FAGNIEZ PL. Postoperative radiation therapy does not increase survival after curative resection for squamous cell carcinoma of the middle and lower esophagus as shown by a multicenter controlled trial. French university association for surgical research. Surg Gynecol Obstet 1991; 173: 123-130.

[6] TACHIBANA M, YOSHIMURA H, KINUGASA S, SHIBAKITA M, DHAR DK, et al. Postoperative chemotherapy vs chemoradiotherapy for thoracic esophageal cancer: A prospective randomized clinical trial. Eur J Surg Oncol 2003; 29: 580-587. http://dx.doi.org/10.1016/S0748-7983(03)00111-2

[7] XIAO ZF, YANG ZY, LIANG J, MIAO YJ, WANG M, et al. Value of radiotherapy after radical surgery for esophageal carcinoma: A report of 495 patients. Ann Thorac Surg 2003; 75: 331-336. http://dx.doi.org/10.1016/S0003-4975(02)04401-6

[8] ZIEREN HU, MULLER JM, JACOBI CA, PICHLMAIER $\mathrm{H}$, MULLER RP, et al. Adjuvant postoperative radiation therapy after curative resection of squamous cell carcinoma of the thoracic esophagus: A prospective randomized study.
World J Surg 1995; 19: 444-449. http://dx.doi.org/10.1007/ BF00299187

[9] OKAMOTO T, TSUBURAYA A, KAMEDA Y, YOSHIKAWA T, CHO H, et al. Prognostic value of extracapsular invasion and fibrotic focus in single lymph node metastasis of gastric cancer. Gastric Cancer 2008; 11: 160-167. http://dx.doi. org/10.1007/s10120-008-0473-8

[10] WIND J, LAGARDE SM, TEN KATE FJ, UBBINK DT, BEMELMAN WA, et al. A systematic review on the significance of extracapsular lymph node involvement in gastrointestinal malignancies. Eur J Surg Oncol 2007; 33: 401-408. http://dx.doi.org/10.1016/j.ejso.2006.11.001

[11] SNYDERMAN NL, JOHNSON JT, SCHRAMM VL, JR., Myers EN, Bedetti CD, et al. Extracapsular spread of carcinoma in cervical lymph nodes. Impact upon survival in patients with carcinoma of the supraglottic larynx. Cancer 1985; 56: 1597-1599. http://dx.doi.org/10.1002/1097-0142(19851001)56:7<1597:: AID-CNCR2820560722>3.0.CO;2-5

[12] BERNIER J, COOPER JS, PAJAK TF, VAN GLABBEKE M, BOURHIS J, et al. Defining risk levels in locally advanced head and neck cancers: A comparative analysis of concurrent postoperative radiation plus chemotherapy trials of the eortc (\#22931) and rtog (\# 9501). Head Neck 2005; 27: 843-850. http://dx.doi.org/10.1002/hed.20279

[13] SAKAI M, SUZUKI S, SANO A, TANAKA N, INOSE T, et al. Significance of lymph node capsular invasion in esophageal squamous cell carcinoma. Ann Surg Oncol 2012; 19: 1911-1917. http://dx.doi.org/10.1245/s10434-012-2232-7

[14] TANABE T, KANDA T, KOSUGI S, IKEDA Y, MAKINO $S$, et al. Extranodal spreading of esophageal squamous cell carcinoma: Clinicopathological characteristics and prognostic impact. World J Surg 2007; 31: 2192-2198. http://dx.doi. org/10.1007/s00268-007-9204-2

[15] BABA M, AIKOU T, NATSUGOE S, KUSANO C, SHIMADA M, et al. Lymph node and perinodal tissue tumor involvement in patients with esophagectomy and three-field lymphadenectomy for carcinoma of the esophagus. J Surg Oncol 1997; 64: 12-16. http://dx.doi.org/10.1002/(SICI)10969098(199701)64:1<12::AID-JSO3>3.0.CO;2-S

[16] METZGER R, DREBBER U, BALDUS SE, MONIG SP, HOLSCHER AH, et al. Extracapsular lymph node involvement differs between squamous cell and adenocarcinoma of the esophagus. Ann Surg Oncol 2009; 16: 447-453. http://dx.doi. org/10.1245/s10434-008-0248-9

[17] COX JD, STETZ J PAJAK TF. Toxicity criteria of the radiation therapy oncology group (rtog) and the european organization for research and treatment of cancer (eortc). Int J Radiat Oncol Biol Phys 1995; 31: 1341-1346. http://dx.doi. org/10.1016/0360-3016(95)00060-C

[18] CHEN J, PAN J, ZHENG X, ZHU K, LI J, et al. Number and location of positive nodes, postoperative radiotherapy, and survival after esophagectomy with three-field lymph node dissection for thoracic esophageal squamous cell carcinoma. Int J Radiat Oncol Biol Phys 2012; 82: 475-482. http://dx.doi. org/10.1016/j.ijrobp.2010.08.037

[19] CHEN J, ZHU J, PAN J, ZHU K, ZHENG X, et al. Postoperative radiotherapy improved survival of poor prognostic squamous 
cell carcinoma esophagus. Ann Thorac Surg 2010; 90: 435-442. http://dx.doi.org/10.1016/j.athoracsur.2010.04.002

[20] METZGER R, BOLLSCHWEILER E, DREBBER U, MONIG SP, SCHRODER W, et al. Neoadjuvant chemoradiotherapy for esophageal cancer: Impact on extracapsular lymph node involvement. World J Gastroenterol 2010; 16: 1986-1992. http://dx.doi.org/10.3748/wjg.v16.i16.1986

[21] LERUT T, COOSEMANS W, DECKER G, DE LEYN P, ECTORS N, et al. Extracapsular lymph node involvement is a negative prognostic factor in $\mathrm{t} 3$ adenocarcinoma of the distal esophagus and gastroesophageal junction. J Thorac Cardiovasc Surg 2003; 126: 1121-1128. http://dx.doi.org/10.1016/S00225223(03)00941-3

[22] CRAWFORD J, OZER H, STOLLER R, JOHNSON D, LYMAN $\mathrm{G}$, et al. Reduction by granulocyte colony-stimulating factor of fever and neutropenia induced by chemotherapy in patients with small-cell lung cancer. N Engl J Med 1991; 325: 164-170. http://dx.doi.org/10.1056/NEJM199107183250305 